\title{
Decision-Making for Crisis Management of Power Distribution Networks
}

\author{
Amir Hossein JAHANIKIA ${ }^{1}$, Vahidreza YOUSEFI ${ }^{2}$, \\ Ehsan MEHRABANFAR ${ }^{3}$, Negar KAVOOSI KHOSROWSHAHII ${ }^{3}$ \\ ${ }^{1}$ BSc. MBA, HRM PhD Student at P.N University, Tehran, Iran. \\ ${ }^{2} \mathrm{PhD}$ Candidate of Construction and Project Management, University of Tehran, Tehran, Iran. \\ ${ }^{3}$ Department of Management, Science \& Technology, Amirkabir University of Technology, \\ Tehran, Iran. \\ e.mehrabanfar@aut.ac.ir
}

This paper suggests a model to solve crises in power distribution network by using spreadsheets in order to make an optimum decision in this regard. Importance of crisis management in power distribution network is investigated from various aspects. Reductions in off times and immediate returns of power, as well as undistributed energy along subscribers'satisfaction are parameters considered in crisis management power distribution network. This paper solves a case about this issue by spreadsheets in order to provide a new model for decision makers to facilitate solving these kinds of problems.

Keywords: Modeling, Spreadsheet, Crisis Management, Undistributed Energy

1 Introduction

Power distribution network is the endpoint of long, expensive process of power generation, transfer and distribution. The task of this sector is to deliver generated power to subscribers and consumers. In fact, in case of failure incidence in distribution sector, all the expenses to generate and transfer power would be fruitless. On the other hand, due to extent of power distribution network, it is subject to various adverse events. Many of these events occur because of network exhaustion or unpredictable events such as atmospheric ones and unexpected events. Therefore, network reliability is a crucial parameter in distribution network exploitation. On the other hand, occurrences such as storm, flood, and earthquake results in simultaneous blackouts in distribution network. In turn, these blackouts results in subscribers`dissatisfaction as well as increase in undistributed energy of distribution sector that is considerable in terms of economic. Decision-making in such situation is a difficult and complex process that should be taken by network managers to decrease failure time and undistributed energy. Since facilities are restricted during crisis, decisions should be taken considering several parameters and attempts to find optimum. Currently, crisis management decisions are made in distribution sector practically without using advanced software models, while using existing facilities such as advanced computer models and algorithms blackout times and undistributed energy can be reduced to the lowest. In the present article, different types of decision-making models during crisis are examined and a model is presented using Excel spreadsheet to show their performance.

\section{Necessity of Using Decision-making Models}

Decision-making models can be traced back to pre-IIWW periods. At that time, many mathematicians like Kolmogorov began using linear decision-making models. After IIWW, with complexity of decision-making issues, "operational research" was introduced as an effective method to solve very complicated issues [2]. In today world, company managers are faced with complex challenges. At the moment, many of successful companies in various fields try to implement different processes in format of various decisionmaking models. Currently, different issues in social, martial, and economic issues are solved using decision-making models. From 
environment pollution control to increase in airline profitability, all are achieved through precise computer modeling. Now, there is no successful company not using different modeling method for its decisions [1]. Power distribution companies due to their important role is the field of country`s power supply, can benefit from these models to significantly increase their performance. In this article, only one example of efficient decisionmaking models during crisis is presented, though there are many models can be used in distribution companies. Major benefits of using decision-making models are:

1. A marked decrease in blackout time

2. Decrease in undistributed energy, and thus economy saving

3. Decrease in expenses of fixing outage and efficient use of existing facilities

4. Increase in subscribers`satisfaction

5. Decrease in tension and stress in workplace, and thus decrease in accidents during work

In fact, it can be said that decision-making models are powerful tools guiding managers during crisis. In this article, a simple model of linear planning is introduced to make an optimal decision during crisis. Since proposed model is solved using Excel software in Windows it can easily be integrated into other network management software such as ENOX or other software. Using proposed methods and adding them to network management software can incredibly increase network management capabilities.

\section{Decision-making Models and Their Implementation}

Decision-making models are divided into two categories: 1) deterministic models in which all parameters are assumed deterministic, and 2) probability models that are provided in uncertain situation [3]. In these models occurrence of a phenomenon is dependent to its possibility. For example, entrance of a company into business context s dependent to its industry`s possible status. It has to be mentioned that in both of these categories data are qualitative or quantitative. In most of decision-making models it is tried to replace qualitative data with quantities ones. For a model to be applied in a real context, it should have some features. Figure 1 shows decisionmaking cycle and its application in real context.

Table 1. Modeling cycle and its implementation [4]

\begin{tabular}{|c|c|}
\hline \multirow{2}{*}{ Formulating } & Problem Statement \\
\cline { 2 - 2 } & Model Formulating \\
\hline \multirow{2}{*}{ Solving } & Problem Solving \\
\cline { 2 - 2 } & Result Testing \\
\hline \multirow{2}{*}{ Analysis } & Sensitivity Analysis \\
\cline { 2 - 2 } & Results Employing \\
\hline
\end{tabular}

The cycle in Figure 1 is consisted of 3 phases of formulation, solving, and interpretation, each of which has several subsets. Is formulation phase, it is first necessary to define the issue clearly and completely [5]. In the case of crisis management of power distribution network to relove outages using existing maintainance teams with minimum time and cost is inevitable. Regarding existing facilities and situation, in model creating part a model should be selected among valid and known models as the main model with a little changes to solve problem. If there is no known models in this part a new model should be designed. According to selected model related information should be collected. It is clear that valid data compatible with real world result in optimum answer. In major issues collecting primary information is one of the most important parts of model [6]. Next phase is nemed resolving. An optimum answer is calculated for the model using Excel software and the answer is tested. If the answer is not appropriate for the situation, it is necessary to review the model. Testing answer is usually done with further information from other resources and their comparison with primary information. When reliability is achieved with 
validity of primary data but the answer is not compatible with reality then it is again required to review the model. After confirming analysis result there is "sensivity" or "if,then" analysis to adapt model with real world [7]. Usually, model is considered with simplification assumptions with an estimation of real world situation, thus, it is necessary to assess the range of changes in answer with condition of change in input and the model. If input and the model are undergone many changes with little change in answer, it is necessary to retest input and model to ensure reliability. Final step of this cycle is result implementation. Result implementation is usually conducted with continuous scaling of context and situation. Any great changes in situation can effect proper performance of the answer [8].

In the next part of the article, crisis management of power distribution network is modeled.

\section{Modeling Crisis Management of Power Distribution Network}

In this part modeling of decision-making in crisis management of distribution network presented in Figure 1 is introduced.

\section{1 problem definition}

As mentioned before, main task of distribution sector is to maintain continuous and reliable distribution of power energy through the network under its control. But this network may fail due various reasons. Crisis occurs when most part of the network is unavailable due to an event. Usually, crisis in power distribution networks happens during storm and heavy rain and snow. For example, in 10/05/2011, between 22 pm till tomorrow morning 4 am 25 case of simultaneous outages occurred in Shemiranat region due to storm that caused 11 case of outages longer than 5 hours in the network. Dependent to geographical conditions of each region, different crisis happen during a year. Failures of distribution network are divided into 7 major classes: 1. Breakdown of low voltage air network, 2. Breakdown of low voltage ground network, 3. Blackout of $20 \mathrm{~kW}$ air network, 4. BLACKOUT OF $20 \mathrm{~kW}$ ground network, 5. Failure in posts, 6. Failure in lighting sector, and 7. Failure in connections. Each of these failures results in outage in that sector. There is certain group for any type of outage in regions. For example, group of low voltage outage is able to resolve problem in this sector. According to conditions, usually two or more groups are integrated and act multi-purposely. Outages in connections and lighting sectors are not so important; therefore, in problem definition it is assumed that this kind of outage is not occurred in the network. According to the model that would be mentioned in next parts, weight and value of each of these outages are determinable. It is clear that number of regions` maintenance groups is limited and during crisis providing service to all subscribers and solving failures is practically impossible. In such situations, proper management of maintenance groups is important in order to reduce total outage time.

\subsection{Model Creation}

To solve all the decision-making issues there are several models that are selected according to the conditions. In crisis management of distribution network "assignment" model is selected which is a subset of "transportation" models. In this kind of model the aim is to find the best available facility assignment to capacity or external needs. For example, parts supply or medicine distribution is of important functions of this model. In crisis management of distribution network the aim is to assign maintenance groups to network incidents such that minimum outage time and undistributed energy occurs. In the example solved problem it is assumed that region power has two service centers for incidents. The number of these centers is high or low according to the area. For example, power of Shemiran region as a subset of Tehran Power Distribution Company has 3 operational zones. Nevertheless, the number and location of operational zones and groups located in them can be solved as an "operational study" problem named "Set-covering" using Excel software, but addressing this subject is out of the scope present study. Figure 2 shows a schematic of an assumed scenario in an assumed area. 


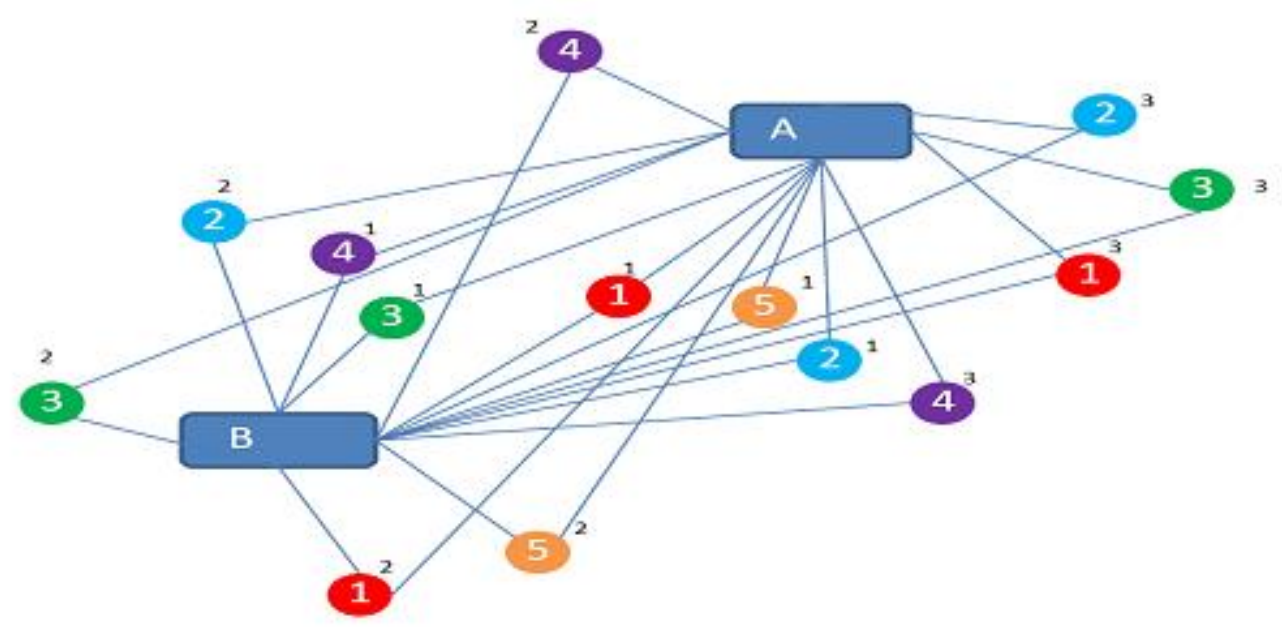

Fig. 1. A schematic of an assumed crisis scenario in an area with two operational zones

In this scenario it is assumed that 14 simultaneous incidents have occurred in the network. Circles indicate defect occurrence and its number determines its type. Thus, number 1 shows outage of low voltage air network and other numbers accordingly show outage in related sectors. In this way, 1-1 is the outage number 1 and type 1 . On the other hand, groups of these 3 zones are located as table (1) shows. Also, it is assumed that region groups are single-purpose and only can solve breakdowns of their own zone.

Table 2. Composition of expert groups located in regions

\begin{tabular}{|c|l|l|l|l|l|}
\hline Center & $\begin{array}{l}\text { group } \\
\text { type 1 }\end{array}$ & $\begin{array}{l}\text { group } \\
\text { type 2 }\end{array}$ & $\begin{array}{l}\text { group } \\
\text { type 3 }\end{array}$ & $\begin{array}{l}\text { group } \\
\text { type 4 }\end{array}$ & $\begin{array}{l}\text { group } \\
\text { type 5 }\end{array}$ \\
\hline
\end{tabular}

To create the model, variables should be defined first. Accordingly, variables to be optimized must be determined. In this order, variable $\mathrm{X}_{\mathrm{ijk}}$ is defined as follows:

$\mathrm{X}_{\mathrm{ijk}}=$ departure of group type 1 from center I to $\mathrm{k}^{\text {th }}$ breakdown

These variables are defined binary ( 1 and 0$)$. In this way, 1 variable means related group departure towards related defect. For example, if $X_{\mathrm{A} 12}$ is 1 , this shows that one of group types 1 of center $\mathrm{A}$ has to departure towards defect type 1 with number 2. Type and number of defects are specified in Figure 2. Assumed distance of breakdowns with centers A and B are specified in table (2).

Therefore, assuming constant speed of groups`cars objective function can be defined as sum of driving distance of groups that is equal to multiply of binary variable of $X$ in the distance between center and the breakdown that is shown with variable Y. thus, objective function is as follows:
Objective Function-minimize $\mathrm{Z}=\mathrm{X}_{\mathrm{A} 11} \mathrm{Y}_{\mathrm{A} 11+}$ $\mathrm{X}_{\mathrm{A} 12} \mathrm{Y}_{\mathrm{A} 12}+\mathrm{X}_{\mathrm{A} 13} \mathrm{Y}_{\mathrm{A} 13}+\mathrm{X}_{\mathrm{A} 21} \mathrm{Y}_{\mathrm{A} 21}+\mathrm{X}_{\mathrm{A} 22}$ $\mathrm{Y}_{\mathrm{A} 22}+\mathrm{X}_{\mathrm{A} 23} \mathrm{Y}_{\mathrm{A} 23}+\mathrm{X}_{\mathrm{A} 31} \mathrm{Y}_{\mathrm{A} 31}+\mathrm{X}_{\mathrm{A} 32} \mathrm{Y}_{\mathrm{A} 32}+$ $\mathrm{X}_{\mathrm{A} 33} \mathrm{Y}_{\mathrm{A} 33}+\mathrm{X}_{\mathrm{A} 41} \mathrm{Y}_{\mathrm{A} 41}+\mathrm{X}_{\mathrm{A} 42} \mathrm{Y}_{\mathrm{A} 42}+\mathrm{X}_{\mathrm{A} 43}$ $\mathrm{Y}_{\mathrm{A} 43}+\mathrm{X}_{\mathrm{A} 51} \mathrm{Y}_{\mathrm{A} 51}+\mathrm{X}_{\mathrm{A} 52} \mathrm{Y}_{\mathrm{A} 52}+\mathrm{X}_{\mathrm{B} 11} \mathrm{Y}_{\mathrm{B} 11}+$ $X_{\mathrm{B} 12} \mathrm{Y}_{\mathrm{B} 12}+X_{\mathrm{B} 13} \mathrm{Y}_{\mathrm{B} 13}+X_{\mathrm{B} 21} \mathrm{Y}_{\mathrm{B} 21}+X_{\mathrm{B} 22} \mathrm{Y}_{\mathrm{B} 22}+$ $X_{B 23} Y_{B 23}+X_{B 31} Y_{B 31}+X_{B 32} Y_{B 32}+X_{B 33} Y_{B 33}+$ $X_{B 41} Y_{B 41}+X_{B 42} Y_{B 42}+X_{B 43} Y_{B 43}+X_{B 51} Y_{B 51}+$ $\mathrm{X}_{\mathrm{B} 52} \mathrm{Y}_{\mathrm{B} 52}$

Function $\mathrm{Z}$ should be minimized so that groups`access time to breakdown reaches to its minimum. But is minimum should be followed by certain conditions and constraints of the problem. Since number of available groups in each center is restricted according to table (1), following constraints should be considered to solve the problem. These constraints are extracted from each groups` restrictions from table (1).

Minimizing $\mathrm{Z}$ subject to:

$\mathrm{X}_{\mathrm{A} 11}+\mathrm{X}_{\mathrm{A} 12}+\mathrm{X}_{\mathrm{A} 13}=2, \mathrm{X}_{\mathrm{A} 21}+\mathrm{X}_{\mathrm{A} 22}+\mathrm{X}_{\mathrm{A} 23}=2$

$\mathrm{X}_{\mathrm{A} 31}+\mathrm{X}_{\mathrm{A} 32}+\mathrm{X}_{\mathrm{A} 33}=1, \mathrm{X}_{\mathrm{A} 41}+\mathrm{X}_{\mathrm{A} 42}+\mathrm{X}_{\mathrm{A} 43}=1$

$\mathrm{X}_{\mathrm{A} 51}+\mathrm{X}_{\mathrm{A} 52}+\mathrm{X}_{\mathrm{A} 53}=0, \mathrm{X}_{\mathrm{B} 11}+\mathrm{X}_{\mathrm{B} 12}+\mathrm{X}_{\mathrm{B} 13}=1$ 
$\mathrm{X}_{\mathrm{B} 21}+\mathrm{X}_{\mathrm{B} 22}+\mathrm{X}_{\mathrm{B} 23}=1, \mathrm{X}_{\mathrm{B} 31}+\mathrm{X}_{\mathrm{B} 32}+\mathrm{X}_{\mathrm{B} 33}=2$, $\mathrm{X}_{\mathrm{B} 41}+\mathrm{X}_{\mathrm{B} 42}+\mathrm{X}_{\mathrm{B} 43}=0, \mathrm{X}_{\mathrm{B} 51}+\mathrm{X}_{\mathrm{B} 52}+\mathrm{X}_{\mathrm{B} 53}=1$

Note that all the variables $X$ are binary. Other terms to be considered are as follows:

- All variables are non-negative;

- Assume linear-model;

- $\mathrm{X}$ variables are binary, $\mathrm{Y}$ variables are real.

\subsection{Data Collection}

Information needed to solve the problem is easily obtained. Distance between each breakdown and centers A and B is mentioned in table (3). In this table number and type of defects are shown in rows and centers are shown in columns. Despite low voltage dispatch and GIS in regions finding these distances is easily possible.

Table 3. Assumed distance of various breakdowns from centers per km

\begin{tabular}{ccccccccccccccc}
\hline distance & $\mathbf{1 - 1}$ & $\mathbf{1 - 2}$ & $\mathbf{1 - 3}$ & $\mathbf{2 - 1}$ & $\mathbf{2 - 2}$ & $\mathbf{2 - 3}$ & $\mathbf{3 - 1}$ & $\mathbf{3 - 2}$ & $\mathbf{3 - 3}$ & $\mathbf{4 - 1}$ & $\mathbf{4 - 2}$ & $\mathbf{4 - 3}$ & $\mathbf{5 - 1}$ & $\mathbf{5 - 2}$ \\
\hline A & 4.1 & 11.0 & 5.0 & 5.4 & 6.0 & 1.9 & 5.6 & 16.5 & 3.5 & 4.9 & 3.6 & 5.2 & 4.4 & 13.5 \\
B & 4.3 & 3.2 & 12.0 & 6.3 & 4.0 & 15.0 & 3.0 & 2.5 & 21.3 & 4.1 & 4.9 & 6.4 & 4.8 & 4.0 \\
\hline
\end{tabular}

4.4 Model Solving and Finding Optimum Answer

After model identification, now it is the time to solve the problem. Excel software is used to solve this problem. This software has an Add-in named Solver that can be used to solve linear and nonlinear problems. Handling this part of software is so easy. This Add-in is accessible from Data menu. Noteworthy is the ability to use Solver in the format of software like ENOX, so that by outage occurrence and entering data into ENOX finding optimum answer simultaneously is possible.

Figure 4 shows a schematic of model creation in Excel software. To solve the problem in Excel, first variables are defined. Then, objective function is calculated according to existing constraints, or finally optimum function is calculated using facilities in Solver Add-in. Here, regarding definition of function $\mathrm{Z}$ objective function is a vector multiplication of binary variables in the distance between each breakdown to centers A and B. to do this multiplication function SUMPRODUCT of Excel is used.

As presented in Figure 5, it is clear that optimum objective function of this problem is $40.2 \mathrm{~km}$. In fact, minimum mileage of groups that makes outages optimum is $40.2 \mathrm{~km}$. Considering average speed of $50 \mathrm{~km} / \mathrm{h}$ for maintenance groups cars the average of arrival time is about 48 minutes. For example, in $20 \mathrm{~kW}$ power sector of Shemiran region there were 150 cases of outage for 9401 minutes in total in May 2011 that resulted in 114.632 MA/h undistributed energy. Average of blackouts in this case was 63 minutes. Only 150 minutes reduction of this time and assuming 76 Toman for per $\mathrm{kW} / \mathrm{h}$ undistributed energy results in about 140,000 Toman saving. This figure covering a year and considering other types of outages, as well as calculating other secondary expenditures would be very significant. 


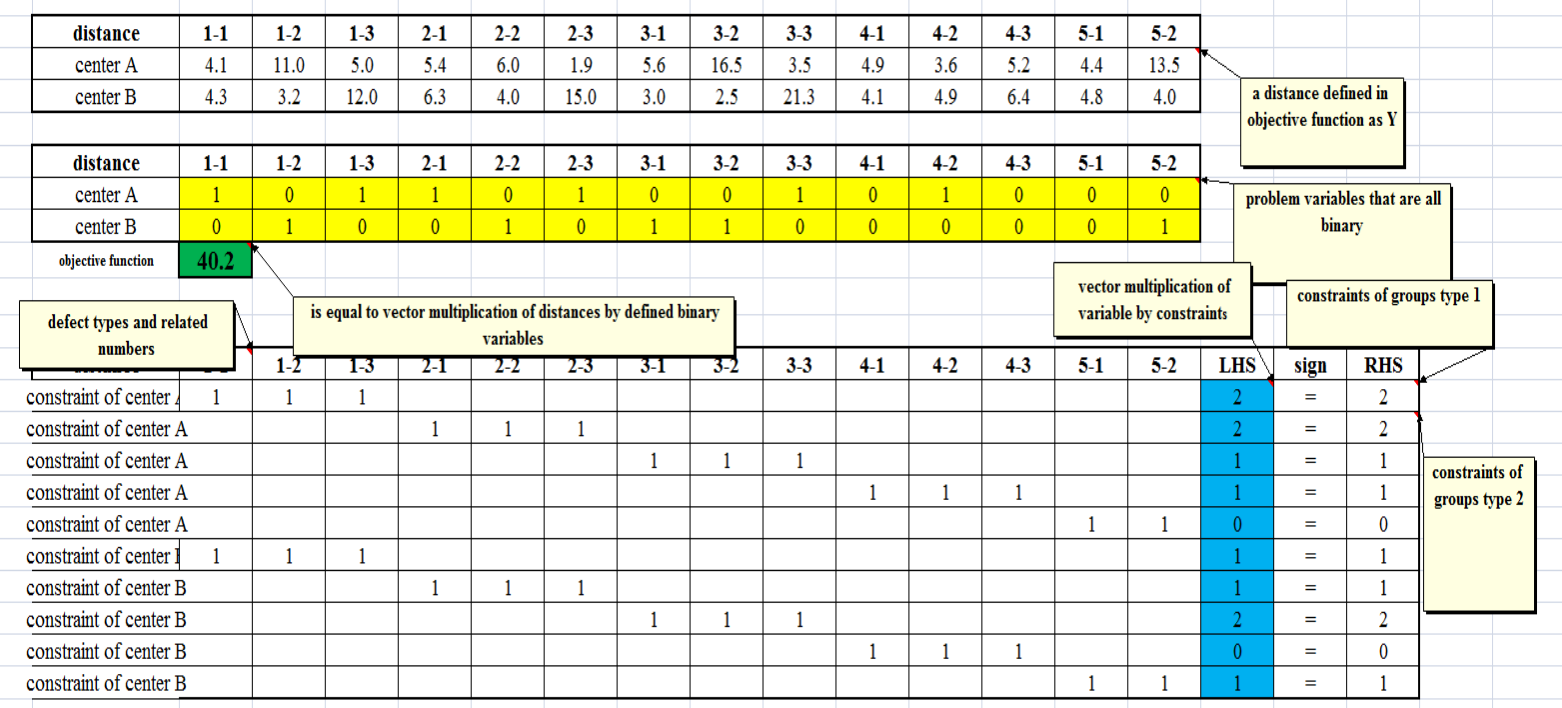

Fig. 2. Solved model using Solver Add-in of Excel

\subsection{Answer Test}

Answer to the problem is shown in Figure 4. Binary variables that are presented in yellow color are calculated by the software. As it is clear in the figure, defect $1-1$ is initialized by group of center A, defect 2-1 is initialized by group type 1 of center B and so on. Objective function is the sum of mileage by groups that is optimized. Examining obtained answers indicates that model is designed properly and answers are compatible with real world. It is worth noting that obtained answers are calculated for one iteration. In other words, available groups are distributed among various breakdowns, therefore, for defects 1$4,3-4$, and 1-5 any group is assigned. If it is going to assign a group for these three defects then the proposed model needs some corrections to change it to an "unbalanced transshipment" model. Because of limitations of the present article this subject is not addressed here.

\subsection{Answer Analysis and Sensitivity}

After solving problem and testing answer compatibility, Solver setting provides a report of answers and sensitivity analysis. Menus related to analysis and answers reports are presented in Figure 5.

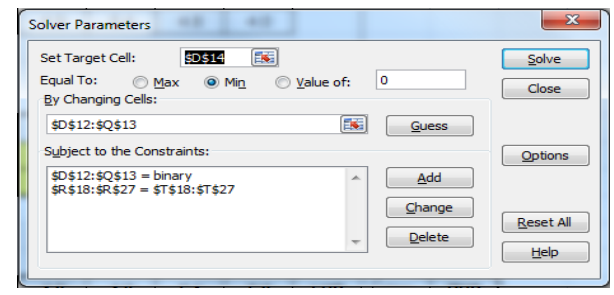

Fig 3. Solver settings

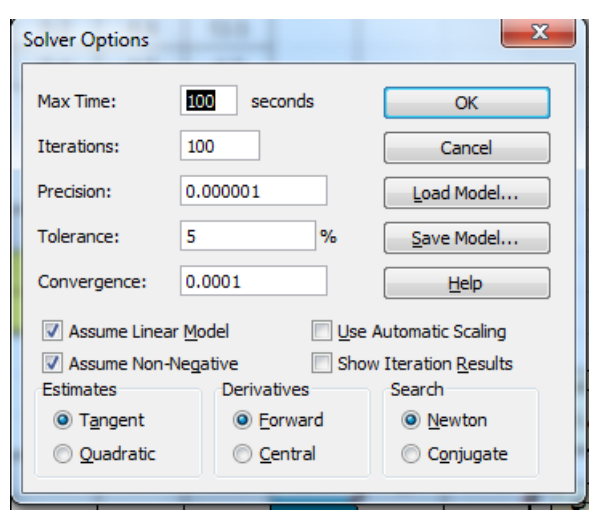

Fig 4. How to determine variables and objective function in Solver

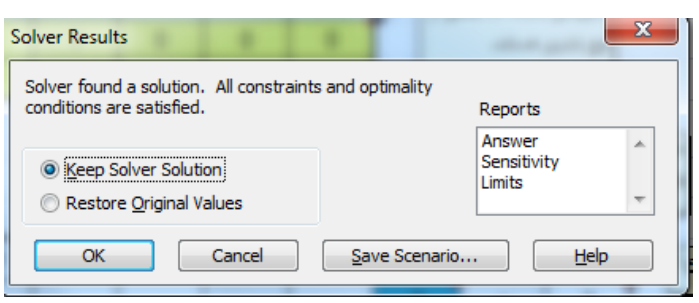

Fig 5. Final answer and sensitivity report 


\subsection{Results Implementation}

After ensuring accuracy of answers, now it is the time to use them. The manner of groups assignment is mentioned in Figure 5. As it is clear, cells of rows D10 to Q10 and D11 to Q11 show the manner of each group assignment to the related defect. In this case, operator or manager, ensured of reliable answers, can easily manage occurred crisis. If additional software like ENOX or GIS software or a combination of them with Solver is used, it is possible to calculate groups assignment in order to reduce costs as well as blackout time.

\section{Conclusions}

Disasters cause heavy damages to power distribution network annually. Part of this damage is due to improper and unscientific management. In the present article, it is tried to use scientific and valid methods based on decision modeling to solve an example crisis in power distribution network. Created model was solved linearly using Excel software and its optimal answer was confirmed. Due to page restrictions of the article it is tried to use simplifying assumptions appropriate to problem situation. Without these assumptions created decision models would have more capabilities to adapt with real world. As objective function shows, financial and nonfinancial losses due to disasters and crisis would be reduced significantly using decision models.

\section{References}

[1] B. Nagraj, B. Render, R. M. Stair Jr, ،"Managerial Decision Modeling with Spreadsheet 1 ،New jersey, (2007).

[2] A. Vazsonyi, The Purpose of Mathematical Models Is Insight, Not Numbers, Decision Line, 21, (1998).

[3] N. Balakrishnan, B. Render, \& R. M. Stair, Managerial decision modeling with spreadsheets, Pearson/Prentice Hall, (2007).

[4] J. L. Higgle, \& S. W. Wallace, Sensitivity analysis and uncertainty in linear programming, Interfaces, vol. 33, no. 4, 53-60, (2003).

[5] J. Current, C. ReVelle, \& J. Cohon, The Minimum-Covering/Shortest-Path Problem, Decision Sciences, vol.19, no.3, 490-503, (1988).

[6] LeBlanc, L. J. Randels, D., \& Swann T. K., Heery International's spreadsheet optimization model for assigning managers to construction projects, Interfaces 30, no. 6, 95-106, (2000).

[7] C. Glassey \& M. Mizarach, A Decision Support System for assigning classes to Rooms, interface, vol. 16, no. 15, 92-100, (1986). 


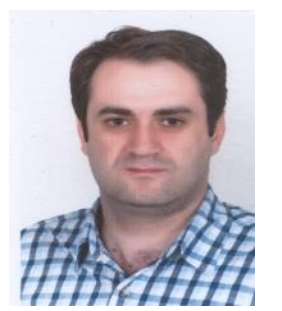

Amir Hossein JAHANIKIA graduated in Electronics Engineering from K.N Toosi University of technology in 2001. He earned his MBA from Amirkabir University of Technology in 2012. He is currently pursuing his education career in HRM PhD in Payame Noor University. His interest is decision making and its applications in different fields.

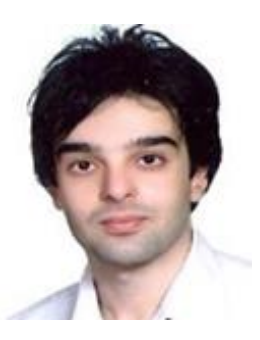

Vahidreza YOUSEFI graduated in Civil Engineering from Iran University of Science and Technology. He earned his MBA from Amirkabir University in 2012. Currently he is a PhD Candidate in Project Management at University of Tehran.

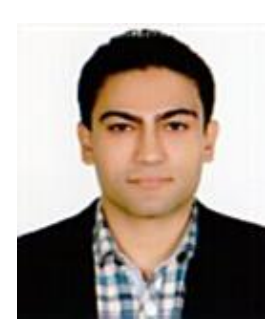

Ehsan MEHRABANFAR; BSc, MBA, MA; graduated from Amir Kabir University of Technology in 2013. He has published many articles in high qualified national and international journals in different aspects of management field. $\mathrm{He}$ is also the founder of international Journal of Modern Management and Foresight (IJMMF). His main research interests include strategic management and business economics.

Negar KAVOOSI KHOSROWSHAHI earned her MBA from Amirkabir University of Technology in 2012. She also holds BSc in electrical engineering. Her main area of work is applying management in electrical industry. She has been involved in national research projects in this regard. 